\title{
Pterygium Popliteal Syndrome Concerning a Case in the Pediatric Surgery Department of the Donka National Hospital (Conakry CHU)
}

\author{
Balla Keita1,2*, Mamadou Alpha Toure ${ }^{1,2}$, Mohamed Lamie Sacko, ${ }^{1,2}$, Mamadou Madiou Barry ${ }^{1,2}$, \\ Mamadou Karamba Kaba ${ }^{2,3}$, Daniel Agbo-Panzo ${ }^{1,2}$
}

${ }^{1}$ Pediatric Surgery Department, CHU Donka, Conakry, Guinea

${ }^{2}$ Gamal Abdel Nasser University of Conakry, Conakry, Guinea

${ }^{3}$ Plastic Surgery Department, CHU Donka, Conakry, Guinea

Email: `ballak2008@gmail.com

How to cite this paper: Keita, B., Toure, M.A., Sacko, M.L., Barry, M.M., Kaba, M.K. and Agbo-Panzo, D. (2022) Pterygium Popliteal Syndrome Concerning a Case in the Pediatric Surgery Department of the Donka National Hospital (Conakry CHU). Open Journal of Pediatrics, 12, 162-169. https://doi.org/10.4236/ojped.2022.121017

Received: December 24, 2021

Accepted: February 27, 2022

Published: March 2, 2022

Copyright $\odot 2022$ by author(s) and Scientific Research Publishing Inc. This work is licensed under the Creative Commons Attribution International License (CC BY 4.0).

http://creativecommons.org/licenses/by/4.0/

\begin{abstract}
Introduction: Popliteal pterygium syndrome is a rare birth defect, combining craniofacial, genitourinary and musculoskeletal abnormalities. It is an autosomal dominant disease caused by a mutation in the IRF6 gene. We report in this observation the $1^{\text {st }}$ Guinean case corrected by the surgical method as well as a review of the literature for a diagnostic and therapeutic approach. Patient and observation: We present the case of a 7-day old male newborn weighing $2700 \mathrm{~g}$ who was received for bilateral cleft lip and palate, lower lip fossa or sinuses, bilateral popliteal pterygium, and triangular skin fold above the hallux. The patient underwent several surgical procedures aimed at correcting these abnormalities. The correction of the pterygium of the lower limbs was ensured by excision of the fibrous band, the tenoplasty in $\mathrm{z}$ of the calcaneal tendon on the right side and the skin plasty in $\mathrm{z}$ in series then immobilized by plaster splints. The immediate postoperative follow-up was straightforward. Conclusion: Popliteal pterygium syndrome is a rare congenital malformation, the diagnosis is primarily clinical. Early soft tissue lengthening surgery and serial z-skin plasty provide better correction of the knee pterygium. Correct correction of facial abnormalities gives the child a better appearance. The management of this syndrome is multidisciplinary.
\end{abstract}

\section{Keywords}

Popliteal Pterygium, Congenital Malformation, Genetic Disease, Pediatric Surgery, Multidisciplinary Team 


\section{Introduction}

Popliteal pterygium syndrome (PPS) is a congenital malformation combining craniofacial, musculoskeletal and genitourinary abnormalities [1] [2]. This rare anomaly was first described by Trélat in 1869 , but the current designation was made by Grolin et al. in 1969 [2] [3] [4]. Only around 100 cases have been reported in the literature [4]. Its incidence is approximately 1 in 300,000 live births [1] [3] [5]. It is an autosomal dominant genetic disease with variable clinical expression [3] [5] [6] [7].

The main clinical manifestations of PPS are cleft lip and/or palate, fossa or sinuses of the lower lip, popliteal girdle, syndactyly, genital and toenail abnormalities [1] [5] [8]. The main most striking feature of this syndrome is the presence of a band of connective tissues extending from the ischial tuberosity to the calcaneus, forming a true web, limiting the joint mobility of the knee [7] [9]. The association of joint stiffness and retraction of posterior soft parts with cutaneous and muscular tightening poses specific therapeutic difficulties [4]. One of the most recommended procedures is the lengthening of the skin and soft tissue by excision of fibrous bands and Z-plasty at an early stage. However, full lengthening is often not achievable because the nerves and vessels at the affected site are short and displaced in the web and attached to adjacent tissues [10]. We report here the description of the first case in Guinea in a newborn corrected by the surgical method as well as a review of the literature for a diagnostic and therapeutic approach.

\section{Patient and Observation}

A 7-day-old newborn was referred to our pediatric surgery department for congenital malformation of the face and lower limbs. He is the $9^{\text {th }}$ child of a consanguineous couple aged 36 for the mother and 56 for the father. The other siblings showed no signs of deformities. The mother had performed 2CPN (prenatal consultation), no obstetric ultrasound, and had not supplemented with folic acid iron during gestation.

The baby was born at term from a eutocic vaginal delivery. His Apgar score was good. At birth he weighed $2700 \mathrm{~g}$, his height was $51 \mathrm{~cm}$ and his head circumference was $33 \mathrm{~cm}$.

On physical examination, the newborn was in good general condition, he was awake and toned. Archaic reflexes were normal. He had a temperature of $37.5^{\circ} \mathrm{C}$, a $\mathrm{SaO}_{2}$ at $99 \%$, a respiratory rate of 36 cycles/min and pulse of 150 beats $/ \mathrm{min}$. he presented a bilateral cleft lip and palate with two fossae or sinuses on the lower lip (Figure 1), bilateral popliteal pterygia assessed at $110^{\circ}$ on the right side and $45^{\circ}$ on the left side. He also had a triangular-shaped fold of skin extending from the base to the top of the nail in the left hallux (Figure 2), the genitourinary organs were normal in appearance. Abdominal and cardiac ultrasounds performed as part of the malformation assessment were normal. The standard radiograph of the lower limbs shows the reliefs of the fibrous band without any bone abnormalities. Doppler ultrasound of the lower limbs showed no vessels in the 


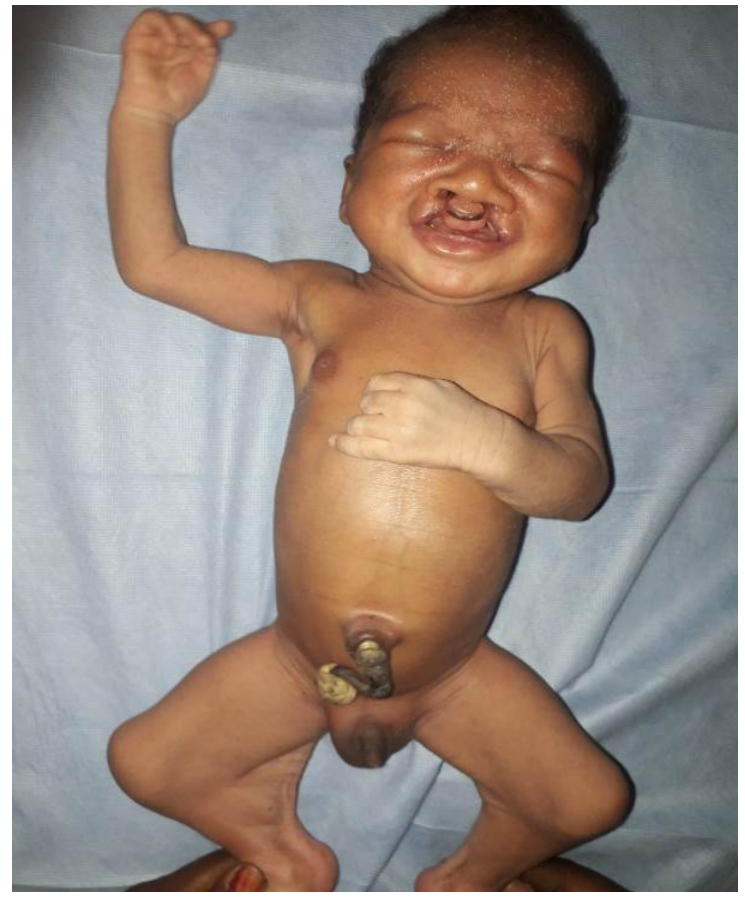

Figure 1. Bilateral cleft lip and palate and bilateral popliteal pterygium.

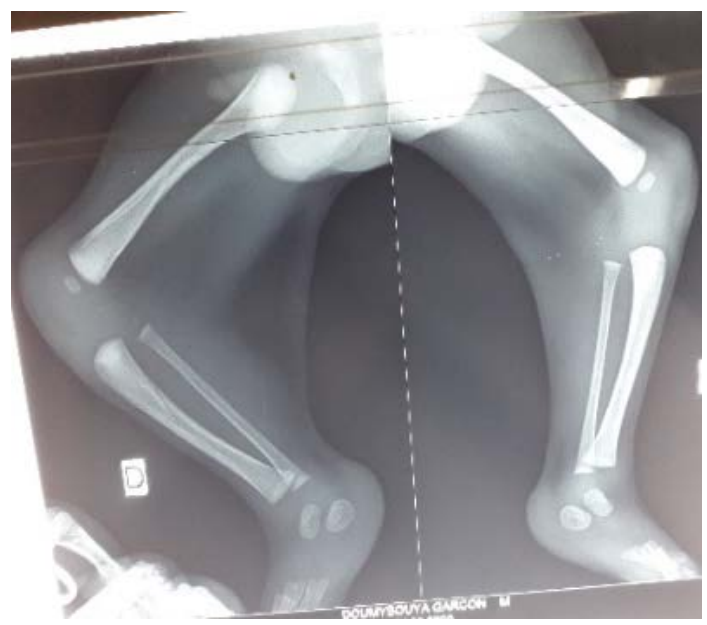

Figure 2. Standard X-ray of the lower limbs showing soft tissue retraction.

fibrous band. The results of the laboratory tests were within normal limits. The surgical procedures were performed as follows. At the age of 1 month, correction of bilateral popliteal pterygia. In the lower right limb, we proceed with the excision of the fibrous band, the dissection of the sciatic nerve, the z-lengthening of the calcaneal tendon (Figure 3 ) and the z-skin plasty in series (Figure 4).

In the lower left limb, dissection and excision of the fibrous band followed by $\mathrm{Z}$ serial plasty of skin. At the end of the surgery, the lower right limb had a residual flessum limited to $20^{\circ}$, that of the left had a complete extension; they were immobilized with plaster splints. Bilateral cheiloplasty was performed at the age of 3 months (Figure 5) and total palatoplasty according to Lamgenbeck at the age of 15 months by the plastic surgeon. 


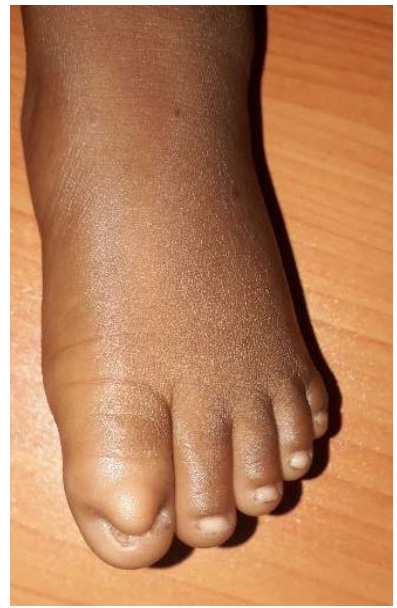

Figure 3. Triangular skin fold over the hallux.

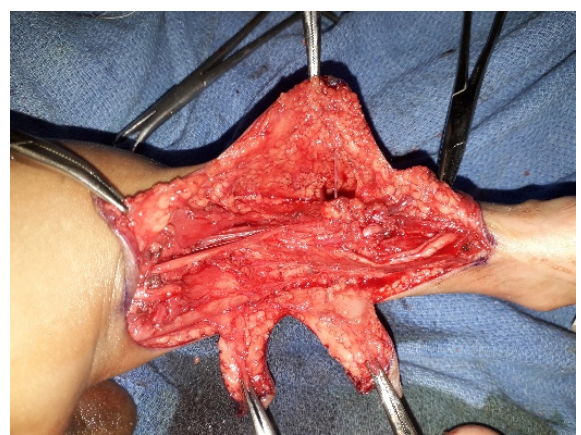

Figure 4. Excision of the fibrous band plus dissection of the sciatic nerve.

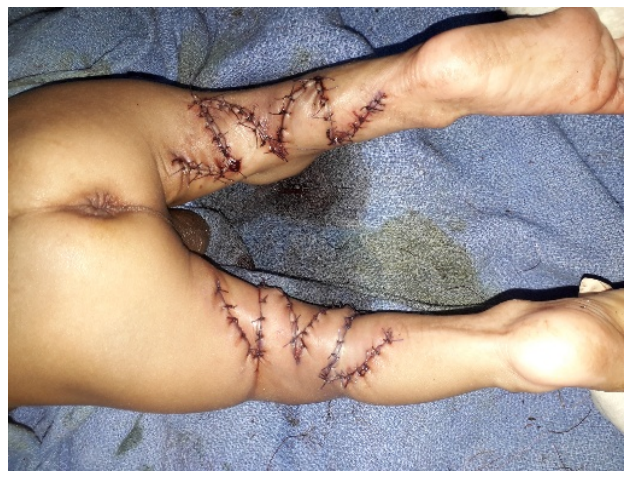

Figure 5. Z-shaped skin plasty in series.

Lower lip sinus excision is scheduled for the next admission. The patient walked at 16 months, the feet are plantigrade (Figure 6), he began physiotherapy with the aim of correcting the residual $20^{\circ}$ flessum in the right knee.

The particularity of our case lies in the fact that the correction of the pterygia was carried out in the same operating time for both limbs. In addition we did not note a genito-urinary anomaly. With absence of syndactyly, the patient has benefited from regular follow-up, once a week for eight weeks, once a month for six months. Currently, he is reviewed every three months. At the last control, the patient walks in a plantigrade position (Figure 7). 


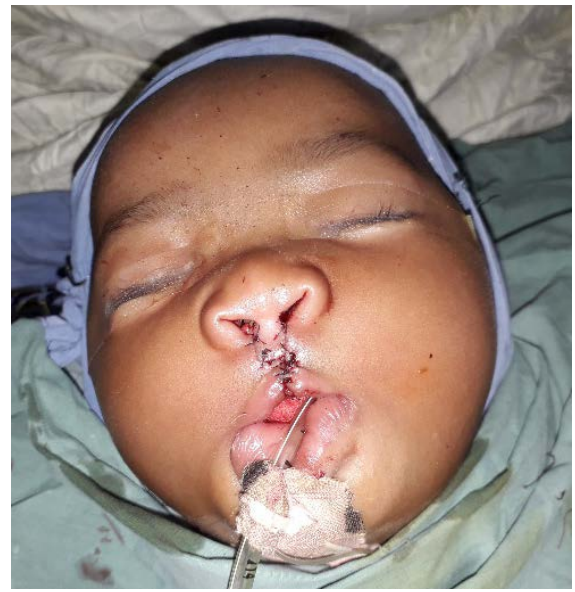

Figure 6. Bilateral cheiloplasty.

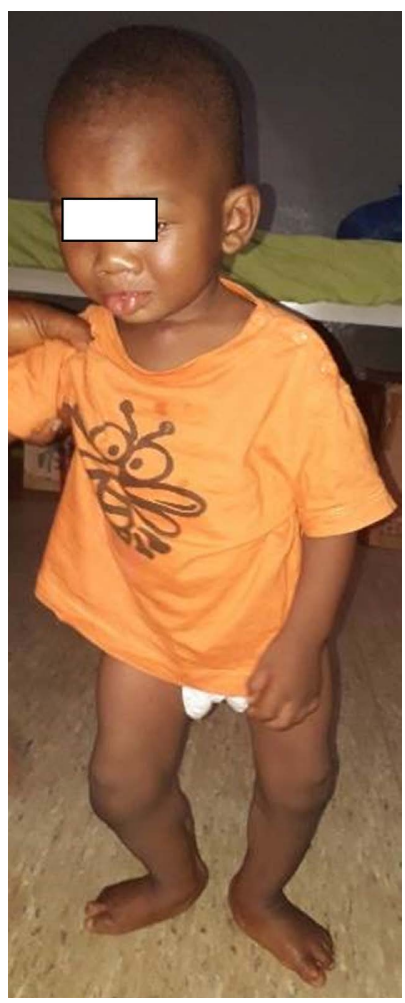

Figure 7. At walking age at 16 months.

\section{Discussion}

Popliteal pterygium syndrome (PPS) is a rare congenital anomaly with autosomal dominant inheritance [3] [5] [7]. This syndrome has some features in common with Van der Woude syndrome (VWS) also inherited as an autosomal dominant condition [1] [8]. The diagnosis of PPS is clinical based on phenotypic characteristics. The main diagnostic criteria are the popliteal strap (58\%), cleft lip and/or palate (93\%), pits or sinuses of the lower lip (46\%), syndactyly (50\%), genital anomalies (37\%) and nail abnormalities (33\%) [8]. The patient described in our observation has the minimum criteria for the diagnosis of this syndrome. 
Heterogeneous mutations in IRF6, which encodes interferon regulatory factor 6 , cause the autosomal form of SPP, although there is evidence for genetic heterogeneity. An autosomal form of lethal type PPS known as Bartsocas-Papas syndrome is characterized by a more severe phenotype than that associated with the autosomal dominant form [11] [12].

The patient described in our observation should be diagnosed with PPS rather than Bartsocas-Papas syndrome.

Various hypotheses have been put forward in an attempt to explain the pathogenesis of PPS. These included a primary microvascular abnormality associated with edema leading to epithelial tissue disruption and adhesion formation, excessive epithelial growth leading to secondary mesenchymal fusion and involvement, primary collagen defect, or loss of tissue. apoptic mechanism [8] [2].

There are different methods of treating PPS. Surgical treatment is preferred because the results of conservative treatment, including casts or serial traction, have not been satisfactory [10]. Most authors agree that early correction is preferable to late correction [4] [13]. Early surgery for the popliteal webs appears to be important for long-term results.

Among the surgical treatments, the elongation of tissues such as skin, muscles and ligaments by resection of the fibrous band and Z-plasty was the most preferred technique. However, this technique is not applicable in many cases where the sciatic nerve is moved through the webbing and attached to fibrous tissue. In this case a nerve transplant is also used after stretching in the soft tissues [10]. Leonardo et al. reported a case of bilateral popliteal pterygium corrected by fibrous band excision and a stepwise Z-shaped skin plasty at 12 and 15 months of age [2]. Oppenheim et al. reported that band excision and Z-plasty was only possible in 2 of 7 patients in their series and that the rest of the cases required secondary operations such as femoral extension osteotomy, femoral shortening or amputation due to severe adhesion to the nerve [13]. The patient in our observation had bilateral popliteal pterygium, more severe on the right. It was corrected simultaneously by excision of the fibrous bands, by $\mathrm{Z}$ lengthening of the right calcaneal tendon and by serial $\mathrm{Z}$ skin plasties.

Occasionally, femoral extension osteotomy, femoral shortening or knee arthrodesis are performed concomitantly [10].

Gradual soft tissue lengthening with an Ilizarov-type external fixator may be one of the optimal procedures when fibrous band excision and z-plasty is not possible due to adhesion to the nerves or vessels of the popliteal pterygium [10]. Although correction is often easier in younger children, the ideal correction age remains difficult to define, balancing the fragility of the bone and the corrective power of the external fixator. This type of treatment is delicate and should be avoided in very young children, before the age of 3 years [4].

The correction of cleft lip and palate is done step by step from the age of 3 months when the child is in good nutritional status. 


\section{Conclusions}

Popliteal pterygium syndrome is a rare disease, associating a spectrum of birth defects without well-defined genetic transmission. Its diagnosis is essentially clinical based on phenotypic characteristics. An early surgical treatment of the pterygium by excision of the fibrous web and a $\mathrm{Z}$ skin plasty in series allows a better correction of the knee flexion and ensures a better result. Correct correction of facial abnormalities makes the child look better

The management of this syndrome must be ensured by a multidisciplinary team.

\section{Conflicts of Interest}

The authors declare no conflicts of interest regarding the publication of this paper.

\section{References}

[1] Ratbi, I., Fejjal, N., Legendre, M., Collot, N., Amselem, S. and Sefiani, A. (2014) Clinical and Molecular Findings in a Moroccan Patient with Popliteal Pterygium Syndrome: A Case Report. Journal of Medical Case Reports, 8, 471. https://doi.org/10.1186/1752-1947-8-471

[2] de Barros Spencer, L.S., Gondim, D.D., Alves, R.V., Da Câmara Silva, R.B.H. and Lopes, V.D.F. (2012) Popliteal Pterygium Syndrome: Case Report and Literature Review. Revista Brasileira de Cirurgia Plástica, 27, 482-486. https://doi.org/10.1590/S1983-51752012000300028

[3] Qasim, M. and Shaukat, M. (2012) Popliteal Pterygium Syndrome: A Rare Entity. APSP Journal of Case Reports, 3, 5.

[4] Solignac, N., Vialle, R., Thévenin-Lemoine, C. and Damsin, J.-P. (2009) Treatment of a Popliteal Pterygium by Ilizarov's Method. Experience of a Continuous Series of Eight Patients. Journal of Orthopedic and Trauma Surgery, 95, 233-239. https://doi.org/10.1016/j.otsr.2009.01.004

[5] Karmakar, S. and Mishra, B. (2020) A Neglected Case of Popliteal Pterygium Syndrome Presenting in Adulthood. Clinical Medical Image Library, 6, 159. https://doi.org/10.23937/2474-3682/1510159

[6] Patel, V., Theroux, M.C. and Reily, J. (2003) Popliteal Pterygium Syndrome with Syngnathia. Pediatric Anaesthesia, 13, 80-82. https://doi.org/10.1046/j.1460-9592.2003.00981.x

[7] Posey, J.E., Dariya, V., Edmonds, J.L., Lee, E.I., Probst, F.J. and Premkumar, M.H. (2014) Syngnathia and Obstructive Apnea in a Case of Popliteal Pterygium Syndrome. European Journal of Pediatrics, 173, 1741-1744. https://doi.org/10.1007/s00431-014-2453-9

[8] Lees, M.M., Winter, R.M., Malcolm, S., Saal, H.M. and Chitty, L. (1999) Popliteal Pterygium Syndrome: A Clinical Study of Three Families and Report of Linkage to the Van der Woude Syndrome Locus on 1q32. Journal of Medical Genetics, 36, 888892.

[9] Hansson, L.I., Hansson, V. and Jonsson, K. (1976) Popliteal Pterygium Syndrome in a 74-Year-Old Woman. Acta Orthopaedica Scandinavica, 47, 525-533. https://doi.org/10.3109/17453677608988732 
[10] Kim, H.-M., Park, I.-J. and Jeong, C. (2009) Treatment of Popliteal Pterygium Using an Ilizarov External Fixator. Clinics in Orthopedic Surgery, 1, 236-239. https://doi.org/10.4055/cios.2009.1.4.236

[11] Leslie, E.J., Standley, J., Compton, J., Bale, S., Schutte, B.C. and Murray, J.C. (2013) Comparative Analysis of IRF6 Variants in Families with Van der Woude Syndrome and Popliteal Pterygium Syndrome Using Public Whole-Exome Databases. Genetics in Medicine, 15, 338-344. https://doi.org/10.1038/gim.2012.141

[12] Kalay, E., Sezgin, O., Chellappa, V., Mutlu, M., Morsy, H., Kayserili, H., Kreiger, E., Cansu, A., Toraman, B., Abdalla, E.M., Aslan, Y., Pillai, S. and Akarsu, N.A. (2012) Mutations in RIPK4 Cause the Autosomal-Recessive Form of Popliteal Pterygium Syndrome. American Journal of Human Genetics, 90, 76-85.

https://doi.org/10.1016/j.ajhg.2011.11.014

[13] Oppenheim, W.L., Larson, K.R., McNabb, M.B., Smith, C.F. and Setoguchi, Y. (1990) Popliteal Pterygium Syndrome: An Orthopedic Perspective. Journal of Pediatric Orthopedics, 10, 58-64. 